\title{
A clínica de quarentena (a quatro mãos): primeiro andamento de uma psicanálise em tempos de pandemia
}

Rita Marta ${ }^{1}$, Tomás Miguez ${ }^{2}$, Inês Ataíde Gomes ${ }^{3}$, Sofia Figueiredo ${ }^{4}$

\begin{abstract}
Resumo
Com o surgir da pandemia, no início de 2020, a proximidade física entre analista e analisando tornou-se não só interdita, como perigosa. Subitamente, os analistas foram obrigados a fechar as portas do consultório, e se alguns suspenderam o trabalho com os pacientes, a maioria iniciou um trabalho por via remota - a teleanálise.

Quatro analistas refletem na sua experiência no ajustamento do setting em tempos de pandemia: a especificidade da situação pandémica relativamente a outras situações em que a realidade externa impõe a utilização de um seguimento remoto; a forma diversa como a pandemia e a alteração do quadro foram vividas pelos diferentes pacientes, e pelos diferentes analistas, mostrando como em psicanálise se trabalha com o campo analítico e como cada díade, na relação transferênciacontratransferencial, torna singular o que ali acontece. A partir desta experiência múltipla de quatro analistas a «tocarem» a sua experiência única, tal como os músicos podem tocar em conjunto uma só sonata, cada um com a sua diferente melodia, foi possível fazer emergir uma série de questões, colocadas numa reflexão final.
\end{abstract}

Palavras-chave

Pandemia, Teleanálise, Alterações do setting

1 Psicóloga Clínica e Psicanalista. Membro Associado da Sociedade Portuguesa de Psicanálise e da IPA. Cofundadora da Clínica Rorschach - Avaliação, Intervenção e Formação em Psicologia Clínica Psicanalítica.E-mail:ritamarta7@gmail.com

2 Psicólogo Clínico. Membro Candidato da Sociedade Portuguesa de Psicanálise.E-mail:tomasmiguez@hotmail.com

3 Psicóloga Clínica. Membro Candidato da Sociedade Portuguesa de Psicanálise.E-mail: inespsiz@gmail.com

4 Psicóloga Clínica. Membro Candidato da Sociedade Portuguesa de Psicanálise. Hospital CUF Sintra. E-mail: asrfigueiredo@gmail.com

( ) do Autor 2021. Publicado online em https://rppsicanalise.org, sob a Licença Creative Commons Atribuição-NãoComercial 4.O Internacional. Seguindo a exigência da preservação do anonimato dos pacientes e da confidencialidade, o material clínico é apresentado com alteração da identidade do paciente e de dados clínicos.

\section{PRELÚDIO DE UMA NOVA REALIDADE}

Em janeiro de 2020, um pequeno vírus foi fechando, de este para oeste, as portas do mundo. Em março, foi a vez de Portugal entrar em quarentena. De forma súbita e inesperada, os analistas foram obrigados a fechar as portas do consultório, e se alguns suspenderam o trabalho com os pacientes, a maioria iniciou um trabalho por via remota - a teleanálise - através de um dos múltiplos aplicativos que permitem a comunicação a distância. 
Que acontece quando surge uma crise súbita, que ameaça ambos, paciente e psicanalista, e os fecha em casa, obrigando-os a estar fisicamente separados e a criar uma relação a distância?

Se é verdade que a psicanálise remota tem vindo a tornar-se gradualmente numa prática comum, para fazer frente às circunstâncias da realidade do paciente (trabalho que exige deslocações frequentes, fobias, etc.) que impossibilitam um setting presencial, a situação pandémica introduz uma outra realidade universal: uma realidade que além de ser comum aos dois, introduz o medo real da morte e uma distância física forçada, que impede a proximidade corporal na relação terapêutica.

Em tempo de crise, a vida fica interrompida, assim como poderá ficar todo um trabalho de elaboração e reflexão emocional. O divã, lugar de segurança e contenção onde o paciente repousa e se deixa ir nos caminhos da associação livre, fica suspenso, o corpo e a mente entram em estado de emergência. Como diz Luis Martin Cabré (2020), esta crise, na sua ligação com a possibilidade de morte, dota-a de características semelhantes às situações traumáticas — «uma violação psíquica, uma situação que irrompe violentamente, de forma inesperada, que não se representa mas se presentifica bruscamente, provocando uma reação de surpresa, de choque, uma reação paranoide ou o desmentido» (p. ) - , conduzindo a uma alteração da temporalidade: «enquanto na claustrofobia e agorafobia existe uma deformação na relação com o espaço, aqui alterou-se a relação com o tempo, o tempo ficou paralisado, quieto, vazio, faltam as palavras» (Marta, 2020, p.).

Estarão as funções do psicanalista - acolher, conter, transformar (Franco, 2003) - afetadas? Ser-lhe-á possível acolher e sobrevoar as turbulências do seu mundo interno, mesmo com a presença excessiva de uma realidade externa ameaçadora? Será capaz de estar recetivo aos terrores profundos dos pacientes e não lutar contra a corrente? E de que modo a forma como o analista está a lidar com a pandemia influencia o seu estar com os pacientes? (Miguez, 2021)

Quatro psicanalistas tocam a quatro mãos a «música» composta entre analista e paciente durante os primeiros sete meses da pandemia Covid-19.

\section{CORPO AUSENTE OU CORPO PERIGOSO? ESPECIFICIDADES DO TELEDIVÃ EM PANDEMIA}

(Pela mão do Analista I)

É interessante pensarmos na questão particular da alteração do setting em situação de pandemia justamente pela sua especificidade relativamente a outras situações (por exemplo, quando o paciente se desloca temporariamente para longe) nas quais é utilizada a terapia remota: (1) a vivência do medo (da morte, das separações, pessoais ou do analista), e a forma como cada personalidade integrou/projetou na Covid-19 outros medos (por exemplo: pacientes fóbicos ou paranoides); (2) a vivência do confinamento/ paragem: alguns pacientes referem dificuldade em estar confinados/fechados (claustrofobia ou angústia de separação), mas por outro lado a crise e a paragem podem constituir catalisadores de processos de elaboração e transformação; (3) o setting remoto e a forma como é vivido pelos diferentes pacientes - que pacientes se recusam a fazer a alteração do setting?; (4) os benefícios secundários: do paciente (por exemplo, pacientes com fobia social que ficam aliviados por não ter de socializar) e do analista (ficar no conforto da sua casa).

\section{A teleanálise e 0 «corpo ausente»}

Ainda antes da pandemia, a minha prática regular, há mais de cinco anos, com terapia remota em situações em que a análise presencial não é possível (pacientes que vivem ou trabalham longe, períodos longos de ausência no estrangeiro, etc.) tornou a alteração do setting durante a pandemia qualquer coisa de muito natural. A partir do momento em que ficámos confinados e foram dadas instruções para o distanciamento físico, rapidamente optei pela teleanálise sem imagem (telefone ou Skype sem imagem), para mim a forma mais capaz de se aproximar do 
setting psicanalítico. De facto, além de durante uma sessão de análise haver ausência de contacto visual, a imagem no ecrã é muito diferente da imagem presencial (distância muito próxima e bidimensional), enquanto a voz à distância se aproxima muito da situação real. Além disso, parece-me existir uma continuidade entre a escuta da voz e a escuta interna, permitindo uma melhor atenção flutuante no analista e associação livre no paciente. Escuto os meus pacientes com o olhar perdido ou fixado num objeto externo que não vejo, e na minha mente são as imagens do terceiro analítico que se vão desenhando. Escuto aquilo que dizem e aquilo que silenciam, as hesitações e o afeto que ecoam com as palavras, enquanto gradualmente se desenham imagens e se constroem significados.

Estas questões têm sido discutidas pelos psicanalistas nos últimos anos e não são unânimes (Ehrlich, 2019; Gutiérrez, 2017; Marta, 2016; Scharff, 2013).

Tal como agora, o confinamento forçado pela pandemia Covid-19 obrigou a um trabalho a distância que permitisse manter o trabalho clínico - já há vários anos que os meus pacientes me «empurraram» para a teleanálise - em situações em que foram viver para longe - como forma de dar continuidade ao trabalho analítico. De facto, perante a minha sugestão de oferecer indicação de outro terapeuta (o que em tempo de pandemia não seria possível), preferiram dar continuidade à relação «possível» comigo, escolhendo manter um vínculo objetal «suficientemente bom» em vez de cortar a relação, criando uma ligação a distância, mas não distante (Ehrlich, 2019), à espera da primeira oportunidade para um retorno à relação em presença física.

Este tempo de prática a distância tem-me permitido refletir na forma como esta alteração do setting interfere no trabalho/relação analítica. E, efetivamente, a minha experiência (em particular, mais fácil de observar através da alternância entre sessões presenciais e remotas) indica que a presença corporal do analista (e do seu consultório, para onde o paciente tem de se deslocar regularmente) constitui, assim como as horas regulares e a atitude analítica, uma parte impor- tante do quadro - o «setting corporificado» (Lemma, 2014) -, desempenhando uma função de «holding» e promovendo também movimentos transferenciais mais intensos e uma regressão primária mais acentuada (Marta, 2016). Além disso, também o analista sentado atrás do paciente parece ter acesso a uma informação inconsciente mais profunda - muitas vezes, através do $\mathrm{Eu}$ corporal (Lemma, 2014; Hardt, 2019; Marta, 2019; Miller, 2019), de ambos, analista e analisando por oposição à presença do ecrã, que convoca uma atenção focada e um esforço acrescido de concentração (muitos psicanalistas, em prática remota durante a pandemia, queixaram-se de ficarem muito mais cansados).

E ainda, em teleanálise o silêncio parece ser mais difícil de suportar para ambos: com a distância, o analista parece ter necessidade de maior intervenção verbal, como se esta fosse uma forma de, na ausência do corpo, se mostrar presente, o que parece estar de acordo com uma tendência de a distância física convocar fantasmas de separação e abandono, que, por outro lado, podem ser interpretados e trabalhados (Ehrlich, 2019; Marta, 2011, 2019).

Lembro-me do «Manuel», um jovem de 17 anos, com uma forte sintomatologia depressiva acompanhada de muita angústia, que sempre vivera expatriado num país europeu, e cuja mãe, depois de consultar vários psicólogos e psiquiatras no país onde residiam, percebe que o filho precisa de um tratamento na língua materna e me pede ajuda. O Manuel é muito inteligente e um aluno brilhante, mas com uma angústia de execução muito forte, uma enorme insatisfação consigo mesmo, um conflito permanente entre a ansiedade/cansaço perante as exigências externas e o sentimento de vazio/estar perdido nos momentos de descanso. Em criança, conta a mãe, desde muito cedo tinha rituais obsessivos, e uma dificuldade em estar confortável na relação com as outras crianças, apesar de ao longo da sua vida ter construído várias amizades e ter atualmente uma namorada estável (com quem tem uma relação de forte interdependência).

Durante a primeira consulta com ele, presencial, veio-me a imagem de um menino fechado 
numa bola de sabão, de onde não conseguia sair, que o protegia e ao mesmo tempo o impedia de entrar num verdadeiro contacto com o outro.

$\mathrm{Na}$ interação com os outros, a espontaneidade é impossível, o Manuel sente que tem de ter muito cuidado para não os ofender, ou afastar, receando tornar-se demasiado estranho ou pesado para eles, conduzindo a uma vivência interna em que nunca pode estar completamente descontraído, e em que se sente sempre só.Desde o infantário, e ao longo da sua escolaridade, sempre que alguma coisa corria mal nunca pedia ajuda a um adulto, procurando resolver tudo sozinho, numa espécie de hiperautonomia precoce.

Nesta primeira consulta, devolvo-lhe a imagem do menino fechado na bola de sabão, que surgira na minha mente, e proponho psicanálise duas vezes por semana, a distância, com sessões presenciais durante as férias (Natal, Páscoa e Verão).

Durante o trabalho remoto, foi possível criar o vínculo, manter uma ligação que foi de extrema importância em momentos de muita angústia e fazer várias interpretações sobre as fantasias internas do Manuel (por exemplo, um ditador interno que o mandava funcionar permanentemente e um medo muito grande de parar e ficar perdido no vazio). Estas ideias eram compreendidas por ele a um nível racional, sem, no entanto, serem vivenciadas emocionalmente. Além disso, contratransferencialmente, eu não me conseguia sentir uma analista contentora, pelo contrário, sentia-me, apesar do discurso aparentemente fluente e solto do Manuel, mantida a distância e empurrada para uma posição racional e assexuada (não materna, não feminina), por vezes imaginando-me mesmo uma espécie de robô (contraidentificação projetiva?). Tudo isto me fazia pensar em que a falha se situaria ao nível da relação primária, e na necessidade de o ter em presença física no divã e com maior frequência de sessões.

Passados alguns meses de tratamento, Manuel compreende a necessidade de parar, e decide fazer um «gap year» antes de entrar para a universidade. Vem durante um ano viver para Lisboa e combinamos sessões presenciais três vezes por semana.
Quando se iniciam as sessões no divã, todas estas questões se tornam corporais e evidentes, mostrando a profunda dificuldade de entrega do Manuel na relação com a analista. Deitado no divã, ele é incapaz de pousar a cabeça para trás, e quando lhe chamo a atenção para isso, responde: «Levanto a cabeça porque é mais fácil para mim, para me poder concentrar no que vou dizer, em vez de dizer o que me vem à cabeça...»Paralelamente às significações corporais que tornam evidentes, para ambos, a dificuldade de entrega na relação com o outro, adensa-se a relação transferencial/contratransferencial, e surgem enactments. Por exemplo, procura o controlo da relação tentando alterar o horário das sessões de acordo com as suas conveniências pontuais, ficando muito zangado quando o impeço de o fazer.

\section{Analista e paciente em tempos de pandemia: 0 «corpo perigoso»e uma oportunidade evolutiva}

A situação pandémica introduziu uma realidade súbita e brutal que, para lá da necessidade de obrigar a um tratamento psicanalítico remoto, convocou outras questões: o medo da morte, a incerteza, a situação de confinamento. Que alterações a imposição de uma realidade externa ansiogénica e comum a ambos provoca no trabalho analítico? Quais as suas implicações na relação analítica e nos fantasmas do par analítico? Que pacientes foram mais afetados por ela? Nesta situação, é possível manter a técnica, em particular interpretar os fantasmas do paciente e os fenómenos transferenciais e contratransferenciais?

Além disso, ao contrário de outras situações de psicanálise remota, a proximidade física é não só impossível como também perigosa. Poderão estes fatores, para lá da situação de teleanálise, introduzir mudanças na relação analítica? Poderá haver uma alteração da relação transferencial através da igualização da situação para ambos?

Não nos podemos esquecer de que em psicanálise o diálogo se estabelece a partir de duas realidades psíquicas, subjetivas, sendo a reali- 
dade externa importante unicamente na forma como cada sujeito (analista ou analisando) vive internamente esses mesmos acontecimentos. Daí a necessidade de o analista ser capaz de elaborar a sua ansiedade para poder ajudar o paciente, mantendo assim também a hierarquia simbólica da relação. Numa entrevista, a italiana Simonetta Diena (2020), psicanalista didata, de Milão, referia como apesar de a realidade externa ser extremamente difícil e assustadora (Lombardia nos primeiros meses da Pandemia), ela não sentia medo, condição fundamental para poder ajudar os pacientes.

Por outro lado, apesar de a ameaça externa ser comum a ambos, a situação analítica, como refere a psicanalista didata israelita Yael Samuel (2020), nunca é simétrica, mesmo quando os perigos da realidade externa - como nas guerras - são comuns a ambos: «A relação permanece assimétrica, eu manejo o tratamento, decido o setting, continuo a ser a psicanalista.»

Mas, por outro lado, o estar «no mesmo barco» pode colocar o paciente numa situação de maior maturidade, desenvolvendo a «preocupação com o objeto» (Winnicott, 1983). Lembro-me de como, nas primeiras semanas de crise, as primeiras palavras trocadas entre mim e o paciente eram sempre no sentido de saber como estava o outro, e da minha necessidade de colocar inicialmente a imagem no ecrã (que depois tirava), para mostrar ao paciente que eu estava bem, que permanecia a mesma (constância do objeto) e que continuava a poder ajudá-lo.

Relativamente à influência da situação pandémica no trabalho psicanalítico, a minha experiência mostrou-me que, de forma geral, esta foi trazida para a relação terapêutica sobretudo nos primeiros tempos - o medo de morte, o medo do desconhecido, a preocupação com a saúde do analista, a claustrofobia com o confinamento, as angústias de separação com a distância física (do analista e das outras pessoas) - e e que muito rapidamente as preocupações e problemáticas habituais do analisando voltaram para o «divã».

Lembro-me de a analista russa Lola Komarova (2020), psicanalista em Moscovo e presidente do Grupo de Psicanalistas de Moscovo, referir uma experiência semelhante, na qual os pacientes desvalorizavam e não mostravam ansiedade com a pandemia, permanecendo imersos nos seus problemas habituais, o que ela definia como uma negação particular, na qual, apesar da presença do conhecimento intelectual do que estava a acontecer na realidade externa, esta não era investida emocionalmente pelo paciente. Lola compara esta situação com um acontecimento violento ocorrido em Moscovo em 1993, na sequência de confrontos políticos, no qual os tiros que se ouviam na rua perto do seu consultório provocavam o medo na analista, mas não entravam no mundo interno do paciente, que falava como se nada se passasse. «O paciente não investe afetivamente a realidade externa», refere Komarova, «e esta permanece habitualmente lá fora».

O mesmo se passou com o meu paciente Manuel: a pandemia, que começara durante a nossa relação remota, apesar de ser mencionada, não passou a fazer parte dos conteúdos ou da relação analítica, que se manteve imune à realidade externa.

De facto, no trabalho analítico, o tempo da realidade pandémica pareceu ficar submergido pelo tempo do inconsciente, um tempo que Scarfone (2015) chamou de «Tempo Actual» - um tempo que nunca passou e que se mantém prisioneiro de um eterno presente, e que é atualizado na relação transfero-contratransferencial para então poder ser representado (simbolizado) e tornado num verdadeiro passado:

«Na psicanálise, nós não lidamos com o passado, pois se fosse realmente o passado, então não teria o tipo de impacto que observamos na vida de nossos pacientes. Para o que diz respeito ao inconsciente, o que ingenuamente designamos como o passado é, na verdade, ainda bastante ativo, pode parecer morto, mas ainda assombra o presente e é manifesto na compulsão à repetição. Tendo em conta tal repetição, não é verdadeiramente o presente, pois o presente necessariamente flui em direção ao passado, ao passo que este presente, que apelidei de "Unpast", não se torna, por si só, história, nem mantém uma janela aberta para o 
futuro. As formas inconscientes estão ativas, mas num movimento rotatório estéril que é claramente a marca do reprimido, ou seja, que ainda não está acessível numa forma simbólica utilizável.» (p. 2)

Mas, por outro lado, em Psicanálise trabalhamos com o que surge no «campo analítico» (Ferro, 2009), no espaço entre duas mentes, no jogo transferência-contratransferência. Nesse sentido, apesar de ser consensual que o analista deverá ser capaz de elaborar/conter a sua própria ansiedade para poder ajudar o paciente, pergunto-me se a ansiedade real do analista (mais ou menos consciente) com a situação pandémica não poderá ter influência nas ansiedades dos pacientes, num movimento transferencial-contratransferencial - tal como uma mãe, mesmo tendo presente a capacidade de rêverie (Bion) junto do bebé, possa não conseguir evitar a sua própria ansiedade inconsciente. Ilany Kogan (2020), analista didata que trabalhou com vítimas do Holocausto, constatou que os pacientes cujos pais/avós viveram a angústia de Holocausto desenvolveram muito maior ansiedade com a Covid-19, como se esta tivesse reatualizado a ansiedade pré-consciente transmitida pelas gerações anteriores. Não se poderá passar o mesmo na relação analítica? Poderão os analistas que viveram esta crise com maior ansiedade (por vezes, por razões da realidade, como eles próprios ou pessoas próximas terem alguma vulnerabilidade física, ou outras questões mais inconscientes) ter tido pacientes com experiências de maior angústia de morte?

Em conversa com alguns colegas, pude, de forma empírica, observar que alguns analistas que viveram o início da pandemia com maior ansiedade tiveram pacientes que, independentemente da sua problemática de base, trouxeram essa mesma angústia para o divã, e muitos continuam a recusar-se a substituir a terapia remota pela análise presencial. Pergunto-me se a angústia de morte da Covid-19 na relação analítica não estará, além dos fantasmas e vivências pessoais do paciente, fortemente ligada à comunicação transferencial-contratransferencial associada aos fantasmas do analista, tal como acontece na relação da mãe com o bebé.
De facto, alguns analistas referem vivências nos pacientes de estados de angústia intensos, e de uma paralisação da fantasia e da recordação de sonhos, e de uma vivência de um eterno presente (Cabré, 2021). Mas, na minha experiência, esse estado de «choque» aconteceu fundamentalmente no primeiro mês de pandemia - por exemplo, com a existência de insónia - e muito rapidamente o trabalho elaborativo, mesmo a distância, retomou o seu rumo, e no palco da situação analítica, os fantasmas internos dos pacientes fizeram questão de se manter «intactos», mais ou menos disfarçados, permanecendo a realidade externa e global habitualmente lá fora. E sempre que a ameaça externa entrou no «consultório», tornou-se num «pretexto» para a projeção da realidade interna do paciente, como se a realidade pandémica fosse «utilizada» pelo paciente como cenário das suas problemáticas e respetiva elaboração. Os vírus tornaram-se nas personagens persecutórias dos sonhos, por vezes exterminados com um gel desinfetante especial, que depois tornava a paciente numa grávida bonita com um vestido de flores, evidenciando processos de transformação psíquica.

Mas, por outro lado, o confronto com o início da pandemia e o seu confinamento forçado, ao constituir uma situação de emergência universal que nos prendeu em casa ao mesmo tempo que nos impediu de fugir para outro lugar - o mundo inteiro estava contaminado! - , pareceu acordar fantasmas claustrofóbicos. Particularmente interessante foi o facto de a impossibilidade de uma fuga física parecer ter promovido a dificuldade de outras defesas de ordem psíquica, como o evitamento, obrigando a um confronto e elaboração dos fantasmas internos. Ana, ao ver-se fechada em casa, compreende (emocionalmente) a profunda fobia dos aviões. O seu comentário «estou a sentir a mesma ansiedade que sentia dentro do avião» leva-a, no comboio da associação livre (não podia utilizar o evitamento, como no caso do avião), ao episódio de um homem internado com o Coronavírus que fugira do hospital: «Imaginei que ele se deveria também sentir preso...» Tal como ela se sente agora, tal como se sentiu há muito tempo, recorda também, quando era cri- 
ança e a sua mãe fora internada, um medo imenso de que ela morresse. A fobia dos aviões ganha o sentido de uma claustrofobia inconscientemente carregada de emoções de perda e separação.

Noutros casos, o confinamento e a ausência física da analista fizeram emergir problemáticas de separação e dependência. Carla, uma mulher de 38 anos com profundas angústias de separação/intrusão, viveu o confinamento e a relação analítica à distância com um sentimento de falta, de vazio, que pudemos elaborar em conjunto, e talvez por isso foi pela primeira vez capaz de arriscar ir viver na mesma casa com o namorado, fazendo frente às inevitáveis angústias de perda de identidade que surgiam na relação de proximidade e intimidade com ele.

Outras vezes, este mesmo confinamento foi vivido como uma paragem forçada e um silêncio autorizado, abrindo um tempo e um espaço que permitiram uma reflexão interna: este tempo de crise tornou-se num tempo de mudança, de transformação, onde o «depois» se quis diferente do «antes»: uma adolescente, que continuava à espera de crescer, pintou o seu quarto de criança; uma mulher recentemente divorciada saiu de casa dos pais (para os proteger) e em dois dias mudou-se para uma nova casa com os três filhos; uma outra mulher disse: «descobri que quero dar um sentido diferente à minha vida»; e outra ainda: «decidi que vou deixar a cidade e viver no campo». Outros, sem ter para onde fugir, assumiram finalmente uma relação afetiva ambivalente.

Passados dois meses em terapia remota, comecei a sentir uma imensa necessidade da proximidade física dos pacientes, assim como de me deslocar fisicamente para o consultório, para aí me poder deixar impregnar pela minha identidade analítica, ao separá-la também da casa, do computador, etc. Mas o imaginar de um setting asséptico - máscaras, impossibilidade de cumprimentar com aperto de mão, cheiro a desinfetante - mantinha-me ambivalente no recomeço das sessões presenciais. No entanto, assim que fomos autorizados a desconfinar, foram novamente os meus pacientes que me chamaram para fora do «conforto remoto», tal como é o bebé que vai indicando à mãe que está na altura de introdu- zir mudanças. E pude então constatar que mesmo a nova a-normalidade no gabinete rapidamente se tornou, como o vírus, invisível, e pudemos retomar um «certo» trabalho analítico que apesar de tudo tinha ficado suspenso.

Sete meses passaram desde o início de uma pandemia que, ao contrário do que imagináramos durante o confinamento, não desapareceu. E se o vírus se torna gradualmente mais familiar, a estranheza da relação humana mantém-se, quer pela perigosidade da proximidade física (o abraço, o aperto de mão, o beijo, tornados interditos da relação humana), quer pela impossibilidade de adivinhar o interior do outro através das suas expressões faciais. O mundo externo enche-se de «zombies» de máscara que procuram afastar-se do contacto físico, num verdadeiro filme de ficção científica.

Mas no «divã» analítico toda essa «estranha» realidade - o desinfetante e a máscara à entrada, assim como a ameaça e imprevisibilidade diárias - continua a ser filtrada pela realidade interna dos pacientes (e pela atitude analítica do analista) e utilizada para falarem de si. Uma nova interdição à circulação entre concelhos agendada para o fim de semana seguinte é escutada pelos pacientes de forma diferente: uns ouvem o autoritarismo e revoltam-se em manifestações, outros inquietam-se ao imaginar a falta de liberdade externa e confundem-na com uma prisão interna. Ana, que antes sofrera de claustrofobia, imagina-se a fugir para outro lugar, enquanto se recorda da falta que sentiu da piza de figos que o restaurante encerrado durante o confinamento deixara de fazer. Figos que lhe fazem lembrar a figueira que existia numa antiga casa de família, e vem-lhe a imagem da família toda junta, antes de os pais se separarem, a comer figos à sombra da árvore. Chora. Digo-lhe como o sentimento de estar presa de que tanto fala esconde um profundo sentimento de privação afetiva. 


\section{A PANDEMIA E OS SEUS EFEITOS NO PAR ANALÍTICO}

(Pela mão do Analista II)

\section{O confinamento como refúgio}

Nos últimos meses, o mundo ficou de pernas para o ar. Fomos confrontados com uma realidade ameaçadora que nos convoca um enorme desamparo e angústias de morte. A vulnerabilidade e impotência da condição humana ficaram expostas, ameaçando a nossa saúde mental. A pandemia fez-me pensar no mal-estar da sociedade contemporânea, nomeadamente na ideia de sujeito «desbussolado» (Miller, 2004). A reação dos pacientes à pandemia foi naturalmente diversificada. Alguns mostraram-se mais tranquilos do que antes da pandemia, como se esta catástrofe eminente se ligasse a episódios traumáticos vividos no passado e sentissem que agora o trauma era vivido por todos, trazendo-lhes algum alívio. Ficar «preso» em casa traz-lhes mais segurança e não tanto vivências claustrofóbicas. Já anteriormente se sentiam presos a medos e ansiedades que os levavam a viver a vida de uma forma receosa e retraída. Rosa, uma mulher de 40 anos dizia: «No mês passado, sentia-me em pânico, agora estou tranquila em casa... Eu já previra este cenário há algumas semanas, normalmente vivo à frente, procuro antecipar todos os cenários possíveis, e, é engraçado, agora socializo muito mais, através do WhatsApp.» A casa pode ser sentida como um «escudo materno protetor» (Khan, 1963) contra experiências intrusivas que põem em risco a estabilidade e a integração psicológica. Uma proteção que terá faltado na infância, quando era mais necessária. André Green (1988, apud Cintra, 2013) fala de um objeto primário absolutamente necessário para a constituição psíquica. E quais são as funções que o objeto primário precisa de desempenhar, para que se torne tão absoluto? Holding, Continência e Rêverie, ou no dizer de Elisa Cintra (2013): «um objeto que desempenha as funções de acolher, hospedar, agasalhar e sustentar, funções que podemos chamar de antitraumáticas, que coexistem com os aspetos inevitavelmente traumatizantes do objeto materno» (p. ). São estas funções que dão um sentido de continuidade e possibilitam as transformações necessárias para a constituição do sujeito psíquico.

Assim, o confinamento pode ter sido sentido como um movimento defensivo, que é familiar a alguns pacientes, um recolhimento para um mundo isolado e afastado dos outros, sentidos como ameaçadores.

Este refúgio psíquico pode dar alguma segurança, mas em simultâneo gerar experiências de aborrecimento, vazio e desvitalização. Um mundo «ilusoriamente» seguro, onde se evitam transformações psíquicas - não há elaboração onírica nem de lutos, criando vivências contratransferenciais de abandono e solidão no analista.

Mas o confinamento pode igualmente estimular a conceção de um refúgio criativo e reparador, capaz de tolerar e viver ansiedades primitivas. Penso em Maria, uma jovem de 20 anos, que se sente permanentemente tensa, com fantasias de ter de impressionar os outros, caso contrário imagina que será rejeitada. A sua mãe reconhece que vive aterrorizada com a ideia de a sua filha fracassar, já que ela própria se sente uma falhada. A paciente tem uma sensação muito antiga de ter de esconder dos outros os seus verdadeiros sentimentos. Abrahm \& Torok (1995) falam-nos de «todas as palavras que não puderam ser ditas, todas as cenas que não puderam ser rememoradas, todas as lágrimas que não puderam ser vertidas serão engolidas, assim como, ao mesmo tempo, o traumatismo, causa da perda. O luto indizível instaura no interior do sujeito uma sepultura secreta» (p. 151). Habitualmente, Maria sente-se inundada por emoções intensas e violentas de abandono, não conseguindo simbolizá-las. Durante o confinamento, sente-se mais apaziguada e reconhece a importância de termos mantido a psicoterapia, via Skype. Começa a escrever histórias, nas quais projeta muito do seu sofrimento, que me comove, revelando capacidades criativas extraordinárias. Que terá levado Maria a «sonhar» as suas experiências emocionais dolorosas, mais do que nas sessões presenciais? Ter-se-á sentido desamparada com a ausência física do analista e uma possível interrupção da terapia? Maria recorda momentos em que brincava sozinha com 
bonecas, «protegia-me de vivências mais difíceis e de conflitos, era um mundo só meu, ninguém lá entrava... por vezes ainda tenho vontade de pegar nas bonecas, de estar nesse mundo... uma espécie de bunker criativo...». Penso em Ogden (2010), quando defende que «a principal função da análise é a de aumentar a capacidade do paciente em estar vivo para vivenciar ao máximo a plenitude da experiência humana. O crescimento psicológico do paciente envolve a expansão da sua capacidade de experimentar as suas alegrias, tristezas e também naufrágios» (p. 24).

\section{A alteração do setting e a escuta analítica}

Durante a pandemia, alguns pacientes sentiram a mudança brusca do setting como muito perturbadora, revelando narrativas concretas e fragmentadas, dificultando seriamente a escuta do inconsciente e o contacto emocional. Recordo uma paciente que aceitou continuar a análise por Skype, dizendo-me que o fazia «apenas por motivos humanos, não clínicos, para mantermos o nosso vínculo». Seguramente, também eu me senti inquieto e sobressaltado. Senti que fazia um esforço para me sentir ligado e para devolver algo que fizesse sentido. Não fiz interpretações sobre o funcionamento mental destes pacientes, preocupando-me mais em ligar-me a uma experiência humana. Talvez nesses momentos analista e paciente se sentissem ambos vulneráveis e perdidos perante a ameaça provocada pela pandemia. Penso em Ferenczi (1932, apud Hárs, 2015), quando refere que, para reconhecer a vulnerabilidade, é preciso analisar a criança que existe no adulto, análise esta feita através da criança que existe no analista: «A impressão que se tem é a de duas crianças igualmente assustadas que trocam as suas experiências, que em consequência de um mesmo destino se compreendem e buscam instintivamente tranquilizar-se.» (p. 20) No entanto, esta realidade não significa que analista e paciente fiquem no mesmo patamar. Pelo contrário, é a autoanálise do analista que permite e acentua a função analítica.

Alguns destes pacientes referiram que não gostavam de falar ao telefone, nomeadamente com os seus pais, que viviam muito longe. Escutei esta constatação com alguma tristeza, imaginando que um contacto telefónico podia despertar nos pacientes um forte desejo da presença física do outro, algo impossível de se concretizar. Isabel questiona-se sobre o fato de não lhe apetecer ligar à sua mãe, que vive no estrangeiro e com quem tem uma relação próxima e afetuosa. Sinto-me invadido por uma tristeza intensa, fantasiando Isabel a receber um abraço longo de sua mãe. Talvez falar ao telefone acordasse uma «fome afetiva», tornando mais dolorosa a ausência. Quiçá alguns pacientes também sentissem que falar ao telefone com os seus terapeutas aumentava a dor e o vazio da ausência física, sentida como uma perda e um abandono.

Recordo João, um paciente que sempre sentiu desconforto nas sessões realizadas por telefone, e falta da presença física no consultório. João fala da casa dos seus avós como sendo a sua segunda casa. Quando o questionamos acerca de qual é a sua primeira casa, responde: «pois, acho que não sei, realmente nunca tinha pensado nisso e acho que sinto... como se não soubesse ou não tivesse uma primeira casa, o que é muito estranho». Esta resposta revela a fragilidade do mundo interno de João, não tendo interiorizado uma relação privilegiada confiável e protetora que lhe pudesse dar uma capacidade de holding interno. De facto, João sente a sua mãe como uma figura distante e fria, pouco empática e pouco disponível para o ouvir. Também não se lembra de a mãe falar dos seus próprios sentimentos e emoções, sentindo-a como impenetrável. Como se em algumas pessoas a construção da «casa interna» tivesse sido seriamente perturbada nos primeiros anos de vida, dando-lhes a sensação de habitarem uma casa abandonada e desleixada, sem portas e janelas. João não sentiu que foi criando uma boa e genuína pele psíquica, separadora de um mundo externo e um mundo interno: «acho que me sinto quase sempre muito confuso, como se não soubesse se o que penso é meu ou do outro...».

A alteração do setting também perturbou a experiência analítica, nomeadamente na vivência 
de silêncios. Tanto no Skype como no telefone, os momentos de silêncio foram raros. O corpo do analista, a sua respiração, a sua voz e o espaço do consultório são elementos essenciais que suportam os movimentos regressivos dos pacientes, ao contrário das tecnologias, que, por vezes, criam um fator de imprevisibilidade e insegurança, interrompendo bruscamente as ligações. Zeligs (1960, apud Matos, 2014) defendia que nos períodos silenciosos, de regressão oral, tanto as palavras como o silêncio do analista são tomados como «alimento psíquico». E Nacht (1964) sublinhava o valor da relação primária na dinâmica da transferência, fazendo da comunicação não verbal um dos fundamentos da terapêutica psicanalítica, podendo o silêncio ser um fator integrativo. Já Coimbra de Matos (2014) sugeria que é no recolhimento silencioso que o melhor da elaboração psíquica se processa. Desta forma, na teleterapia torna-se mais difícil viver momentos de silêncio e intimidade. Recordo as palavras de um paciente em análise: «já percebi que muito do que aqui vai acontecendo tem que ver com o não dito».

\section{ALTERAÇÕES NO GAMPO ANALÍTICO}

(Pela mão do Analista III)

A resposta psíquica de cada paciente à pandemia e ao confinamento foi naturalmente idiossincrática. Se num primeiro momento houve em muitos uma resposta em espelho, apresentando o reflexo da consternação e apreensão transversal à sociedade portuguesa, muito rapidamente se foi revelando a forma como cada indivíduo usou os seus recursos e as suas defesas na adaptação a uma nova realidade.

Em algumas sessões, a pandemia e o confinamento eram «o tema», noutras passou a ser apenas um pano de fundo que, nunca se ausentando completamente, deixava espaço para novos conteúdos.

Recordo um paciente, em análise há cerca de 10 anos, cujas sessões versaram sempre questões muito concretas do isolamento, dos cuidados ao sair de casa, ao voltar, num excesso de zelo per- manente e limitador, raiando o ritual obsessivo, a que apenas passados largos meses, já no regresso ao trabalho fora de casa e à análise presencial, pôde aceder, ainda que de forma apenas parcial. Pudemos retomar uma questão que tinha vindo a ser trabalhada em outros contextos e que o confinamento veio finalmente legitimar, um sentimento antigo de que o mundo é um lugar perigoso, onde não há lugar para si, em que sendo tão frágil se pode ferir, repetindo a experiência infantil de um estrago sem conserto ou reconhecimento possível.

A reflexão sobre o analista contentor, que precisa de respeitar o tempo do outro e aguardar pelo momento em que uma interpretação pode ser ouvida e acolhida, tornou-se indispensável para receber meses a fio os conteúdos mais concretos - formulação possível de uma angústia em bruto sem possibilidade ainda de ser elaborada.

Outros veem aqui uma possibilidade de afirmar a sua capacidade de se autonomizarem e realizarem novos investimentos libidinais. Ricardo diz-me: «Os meus pais queriam que fosse fazer a quarentena para casa deles?! Eu tenho 34 anos! Eu não me sinto mal por estar sozinho! Gosto!», como que usando este novo contexto social para sedimentar aspetos trabalhados na análise e difíceis de reproduzir no mundo de relações objetais rígidas e tóxicas. Este processo de individuação, longe da mãe real e em contacto com a mãe analista suficientemente boa, foi espaço de crescimento e de compreensão da relação primária, que se foi transformando ao longo dos meses em contactos mais pontuais com a casa materna. Relembrando a fórmula de Bion E=D+T (Esperança igual a Desejo mais Tempo), constatámos que a este homem o confinamento, com todo o isolamento e sofrimento, permitiu redescobrir uma esperança ausente anteriormente: permitiu-se projetar-se no tempo com uma possível relação amorosa significativa que até aqui lhe esteve vedada. Como lembra Fairbairn (2000), «a líbido não é essencialmente procura de prazer, mas procura de objecto. [...] A autêntica finalidade libidinal é o estabelecimento de relações satisfatórias com os objectos; e é, consequentemente, o objecto que constitui a verdadeira meta libidinal. Ao mesmo 
tempo, a forma assumida pela abordagem libidinal é determinada pela natureza do objecto» (p. 177-178). A presença - interna e real — do objeto «mãe», que o mantinha cativo numa relação fusional, impedia a possibilidade de novas identificações que abrem caminho para novas escolhas objetais.

No entanto, para pacientes com organizações psicóticas ou B-L mais desestruturadas, a ausência do analista e/ou do setting foi perturbadora, optando alguns por interromper as sessões. Uma mulher com funcionamento B-L, que com a análise foi construindo rudimentos de pensamentos, mas cuja pseudo-organização está ainda dependente do objeto/analista, foi estando à beira da desorganização, procurando de forma agida objetos substitutos sexualizados (mas não erotizados) que a deixaram progressivamente com uma sensação de maior solidão e vazio. A falha na busca de um limite de si mesma, de um eu-pele que a delimitasse e organizasse, resultou num crescendo de angústia que só pode ser realmente parado no retorno às sessões presenciais. Amaral Dias (2004) fala-nos da «relação com o outro em que o outro, mais do que tudo, é uma segunda pele para uma película falhada do processo mental. A primeira implicação deste fenómeno para o processo terapêutico é que o analista ou psicoterapeuta tem uma dupla face: uma face (que é habitual e esperada) que é a criação de uma capacidade de pensar progressiva por parte do paciente, mas, simultaneamente, uma outra face que é a criação de um continente emocional, isto é, além da criação de um continente relacional é imperativa a criação de um continente mental» (p. 113). Ainda no período de confinamento, perante a necessidade de minimizar a distância com a analista, aspeto fundamental para a sua sobrevivência psíquica na criação deste continente mental de que fala Amaral Dias, e não podendo na altura sentir a presença física, o espaço analítico, colo contentor da sua fragmentação, esta paciente acabou por abordar episódios da sua história ainda não revelados na análise, garantindo assim a proximidade e qualidade do vínculo e reforçando a confiança que deposita na relação analítica.

Embora a reação de cada paciente possa ser trabalhada e, como resposta a uma situação de crise que é, nos ofereça novos vértices de observação na relação analítica, torna-se relevante formular algumas considerações sobre a própria alteração do setting.

Algumas das questões que já vinham sendo discutidas sobre os acompanhamentos on-line ganharam maior relevo, uma vez que fomos compelidos a aderir em massa e rapidamente a esta forma de relação. Lemma (2015) diz-nos que «uma consequência importante das novas tecnologias é como elas estão a transformar a natureza da intimidade [...] éimportante dizer algumas palavras sobre as noções de "real" e "virtual". Quando pensamos em relacionamentos hoje em dia, não podemos deixar de considerar o impacto da ampla conectividade digital portátil. Uma implicação importante disso é que, com o advento de novas tecnologias, os mundos real e virtual começaram a anular-se, ou seja, para a geração atual as redes digitais são cada vez mais uma ampliação do mundo real, e não uma alternativa a ele.” (p. 270) Na verdade incorporamos já aspetos de uma comunicação à distância no nosso dia-a-dia, que tendem a normalizar o uso da tecnologia.

Lemma (2015) faz ainda uma ponte que consideramos interessante na abertura de campo para pensarmos na passagem dos processos terapêuticos para o on-line. Diz-nos: «Como psicanalistas, estamos, no entanto, muito acostumados com a natureza virtual do próprio real, uma vez que este é filtrado por um mundo de relações objetais - que por sua vez é distorcido por processos projetivos e introjetivos - que cria "outros" virtuais carregados de ressonância emocional e que condicionam a forma como experienciamos e agimos. O próprio setting analítico é ele mesmo uma forma de realidade virtual, assim como, poderíamos dizer, o é a transferência.» (p. 271)

Identificámos no período de pré-confinamento que no tecido social predominavam as defesas de negação e omnipotência, numa recusa em entrar em contacto com a angústia inerente à situação pandémica, e naturalmente não excluo psicólogos, psiquiatras e psicanalistas da malha social. Talvez essas defesas não tenham sido 
completamente eficazes, uma vez que falhámos em preparar com os nossos pacientes a transição para uma análise on-line. A evolução da situação na Europa dava todos os indicadores de que em breve Portugal entraria igualmente num período de crise e que medidas mais drásticas teriam de ser tomadas. Analista e analisando estavam a viver e a gerir a mesma realidade.

Sem que muitos de nós tivéssemos encontrado um espaço para refletirmos e prepararmos essa transição - do presencial para o on-line -, ela aconteceu por uma imposição externa. E de repente tivemos os nossos pacientes a abrirem-nos a porta das suas casas. E o próprio analista abriu a porta da sua casa. Nem paciente nem analista projetaram assim a sua relação terapêutica. De repente, vimos cozinhas, varandas, quartos, salas, recebemos a visita da cauda de um e outro gato que, indiferentes à natureza desta chamada em particular, se passeavam agradecidos pelos colos dos donos. Dos pacientes em análise, conheci tetos e candeeiros, algumas paredes, num ajuste caso a caso de qual a forma de comunicação que seria mais confortável, e menos perturbadora desta mudança de setting inesperada. Esta passou rapidamente a ser uma questão completamente secundária nos conteúdos trazidos pelos pacientes.

Mas importa colocar a questão de se o campo analítico é ou não modificado pela introdução de dados da vida do analista que até então não estavam presentes. Será essa informação, agora em poder do paciente, um ruído no par analista-analisando? Talvez o recorrer a chamadas sem imagem, ou a fundos neutros, visasse diminuir esse ruído. Mas não poderemos olhar para essa neutralidade como uma defesa do analista? Privar o analisando do espaço físico do analista não poderá ser também privá-lo do espaço contentor em que o paciente se visualiza e no qual se sente recebido e contido?

Na minha experiência deste tempo de atendimento em casa, não senti qualquer invasão nem curiosidade sobre o que se passava na sala onde realizei as sessões. A casa funcionou como um prolongamento do consultório. Também no consultório estão os meus livros, alguns objetos pes- soais, os quadros que escolhi para preencherem as paredes. Há sempre alguma confusão na minha secretária, e o livro que descansa durante as consultas na mesinha de apoio vai mudando. Muito raramente é feita alguma observação sobre o espaço, mas não é apenas o divã que me representa como objeto contentor. No atendimento on-line, a relação fica privada dos seus elementos sensoriais, da temperatura do consultório, do cheiro, dos sons, do corpo no divã, do espaço/corpo do analista. Durante o período de confinamento, o início e o fim da sessão com imagem face a face foram o garante de alguma continuidade física. $\mathrm{E}$ o desejo de regresso ao presencial foi tanto maior quanto mais necessária é esta contenção através do sensorial.

A nossa apreciação qualitativa não se baseará no termos conseguido manter a análise tal como ela é no registo presencial, mas, sim, no reconhecimento de que para cada paciente com as suas/nossas circunstâncias procurámos, tanto quanto possível, encontrar a melhor solução: «Todos concordamos que a psicanálise depende dos conceitos de resistência, defesa, transferência-contratransferência e interpretação como aspetos essenciais do diálogo psicanalítico. Mas é imperativo que refinemos a nossa compreensão de como a psicanálise se aplica ao mundo moderno, de modo a refletir mudanças na história social e na cultura. [...] A defesa da psicanálise está necessariamente ligada à defesa do ser humano em sociedade. A psicanálise é uma das poucas disciplinas que podem garantir a humanização da tecnologia.» (Aryan, 2013, p. 121)

\section{O SETTING ANALÍTICO NA PANDEMIA. A PRESENÇA DO ANALISTA NA AUSÊNCIA DE FISICALIDADE}

(Pela mão do Analista IV)

Março de 2020. Fomos veloz e vertiginosamente empurrados para o tempo da distopia. A pandemia Covid-19 colocou o planeta no tempo do impensável, do desconhecido. Na teoria lacaniana, falta-lhe significado, rompe com a ordem simbólica. Que é? Que significa? Falta-lhe uma 
narrativa. A perda da normalidade, os espaços de casa aos quais ficámos confinados, a perda da corporalidade uns com os outros (não podemos beijar, abraçar, aproximarmo-nos do outro), qualquer um de nós pode ser contaminado em qualquer parte do mundo sem que dê sequer por isso. Isto rompe com as barreiras de segurança que existiam anteriormente. Nunca esteve tão claro no trabalho de análise que analista e paciente partilham do trauma da realidade do mundo, mundo que outrora continha os espaços seguros.

Outubro de 2020. Já não estamos em isolamento como no início da pandemia, as portas começaram a abrir-se, aparentemente começou a emergir alguma «normalidade», mas na data em que escrevemos este artigo há novamente uma ameaça de confinamento, tendo já sido decretadas novas medidas de restrição de movimentos, e outros países começam a ponderar uma nova quarentena. As sociedades mantêm-se, assim, fechadas. Teremos de aceitar viver com um risco de longo prazo, muito além do que todos nós esperaríamos ou desejaríamos. O vírus continua e é improvável que chegue a risco zero.

Como podemos aprender a viver num presente ameaçado e incerto, que perspetivas de futuro na psicanálise? Que nos mostram na clínica os nossos pacientes? Pensamos na mortalidade, na angústia de morte e de perda, e, consequentemente, interrogamo-nos acerca do setting analítico nas atuais circunstâncias. Será o setting analítico forçado a reinventar-se? E de que maneira?

Perdemos o contacto presencial com os pacientes e a configuração habitual do setting analítico. O recurso à tecnologia (Skype, Zoom, apps, vídeo, FaceTime, telefone) não é novo para muitos de nós. Mas, no aqui e agora em que a pandemia nos mergulhou, para analistas e analisandos a tecnologia surge como algo completamente inédito, sem quaisquer precedentes. Ao contrário de outras circunstâncias, esta mudança de setting para a qual fomos inesperada e rapidamente empurrados (basta pensarmos que de um dia para o outro, sem aviso prévio, tivemos de improvisar e passar todas as nossas sessões presenciais para sessões remotas) não foi provocada por um fator clínico nem por necessidades específicas dos pacientes que exigissem determinado manejo da técnica. O que estamos a viver neste tempo é a reinvenção do setting analítico pela imposição da realidade externa, que nos deixou sem nenhuma outra hipótese.

O espaço seguro tornou-se virtual no presente e num futuro próximo; mesmo que, no atual momento, muitos de nós já recebamos os pacientes no espaço físico do consultório, continuamos a trabalhar num espaço confinado, com as janelas abertas, numa sala com máscara ou a dois metros de distância do paciente. No momento presente, há a possibilidade de novo confinamento. No on-line, encontramo-nos sem o rosto coberto, mas do outro lado do ecrã. Temos de escolher qual o aspeto mais complicado do trabalho presencial, falar de trás de uma máscara que esconde metade do nosso rosto e do rosto do paciente, ou sem máscara e deixando-nos aos dois, paciente e analista, em maior risco. Estranhamente, no espaço virtual, os nossos rostos estão abertos.

Há pacientes que começaram uma terapia na pandemia e aos quais ainda mal conheço o rosto, e cujo meu rosto também eles mal conhecem. Quando não de uma forma evidente, no campo analítico as vivências contratransferenciais no interior da relação com os pacientes dão claramente conta do significado desta ausência. Mas se é verdade que com a pandemia há a perda de um setting, também é verdade que esta perda, na passagem para a análise remota, seja por telefone ou Zoom, bem como as limitações na nova fisicalidade nas sessões presenciais (máscaras, desinfetantes, distância dos corpos), pode ser nomeada, pensada, e é aí que recuperamos a nossa vitalidade psíquica. O espaço da sessão mantém-se como um verdadeiro objeto analítico, o lugar onde é seguro abordar e pensar naquilo que não se conhece.

Ferenczi (2011), em «A Elasticidade da Técnica Psicanalítica», publicado originalmente em 1928, fala-nos do gasto energético que faz com que o analista sinta uma sobrecarga que exigirá, cedo ou tarde, a elaboração de uma higiene particular de si. Não estaremos nós, no tempo de pandemia, sobrecarregados por uma realidade externa excessiva, com todos os seus lutos e per- 
das? Talvez este excesso torne mais do que nunca essencial o recurso à nossa análise pessoal, tal como Ferenczi defende como regra fundamental. Perante a incerteza e o desconhecido, o estranho e o que há nele de familiar, a análise pessoal é o nosso maior significante. Se agora temos uma «elasticidade» no setting analítico, ela só existe porque há um setting interno do analista que foi introjetado, o bom objeto interno, que se nutre das experiências de análise pessoal e da prática clínica.

Talvez o desafio seja o de que esta experiência amplie as possibilidades de exercício da nossa prática e nos traga mais reflexões, que é aliás a vivência que temos tido nos diversos encontros on-line com outros analistas, onde alimentamos também a nossa identidade enquanto analista. As comunicações que ouvimos e lemos, de analistas de todos os cantos do planeta, são reflexões vivas e escutamos precisamente a sua vitalidade no pensamento acerca da morte e das perdas. É aí que testemunhamos a capacidade de criação da própria psicanálise.

Uma paciente inicia terapia remota no contexto da pandemia. Na sessão on-line, conheço-lho o rosto, mas não a conheço ainda com todos os meus sentidos. Faltam as cores, os cheiros, a temperatura, a arquitetura do espaço da sala, os ruídos e ritmos, ou seja, toda a dimensão da sensorialidade e da corporalidade. Ainda não houve um encontro presencial. Mas é neste contexto que, do outro lado do ecrã, a paciente me fala do impacto de uma vida inteira sem palavras para o sofrimento de não conseguir chorar o ter ficado órfã ainda criança. É nesse espaço virtual, onde a relação é mediada pela tecnologia, que a paciente verbaliza o seu desligamento, e é aí que eu posso pensar na perigosidade que sente no encontro comigo, com o outro, não pelo medo do vírus Covid-19, mas pelo medo profundo da relação. A paciente ainda rejeita vir às sessões presenciais, mas deste lado do ecrã, de onde a olho e escuto, e do outro lado, de onde ela me escuta e vê, sinto que a interpretação que eu lhe devolvo atravessa a tecnologia. É como se, por vezes, a barreira virtual quase desaparecesse na totalidade, e noutras vezes o ecrã não conseguisse transpô-la.
Antonino Ferro (2009) diz-nos que, no decorrer da análise, analista e paciente, juntos, começam a encontrar palavras, símbolos e imagens que se reúnem para preencher o campo analítico no espaço entre eles. Para começar a transformar o que não era conhecido em algo conhecido e compartilhado, sendo esse o trabalho da análise.

Winnicott (1969, apud Ogden, 1985) fala do espaço potencial como um espaço psicológico entre a realidade e a fantasia, que se mantém ao longo da vida. É o espaço em que somos criativos no sentido mais comum da palavra; é o espaço em que nos experienciamos a nós próprios como vivos e autores das nossas sensações, pensamentos, sentimentos e perceções corporais. Na ausência da capacidade de gerar espaço potencial, o paciente arranja substitutos defensivos para a experiência de estar vivo (como por exemplo no falso self). A criação desse espaço é o resultado mais poderoso do trabalho entre paciente e analista, porque sentir-se vivo é o ambiente pessoal mais poderoso para o ser humano, proporcionando a possibilidade de mudança. Chegar lá não é um processo simples, agora menos ainda.

Mais do que nunca, o analista é desafiado, e também o paciente se desafia a si próprio ao procurar-nos num esforço para conhecer algo que ainda lhe é desconhecido, mas que quer conhecer, na sua capacidade de manter a sua vitalidade no pensar o vazio, a morte, a incerteza, o não-saber na circunstância viral. Ao aceitarmos o desafio do paciente e ao recebê-lo no contexto da pandemia, em que também nós analistas estamos vulneráveis, não nos podemos deixar invadir por uma híper realidade macro e coletiva, sendo a nossa escuta a escuta da singularidade do paciente e o nosso trabalho o da subjetivação. Há um esforço contínuo para manter o setting interno neste campo de turbulências, sem inibir a nossa capacidade negativa (Bion, 1970). Os fatores do medo, da angústia, dos lutos e perdas precisam de se converter em algo analisável, ou seja, trazidos para o campo das fantasias, defesas e resistências, para se transformarem em objetos psicanalíticos a serem sonhados e interpretados. É no espaço potencial (Winnicott, 1967) que as experiências 
emocionais poderão ser nomeadas, representadas, simbolizadas e transformadas, e em que posições subjetivas poderão ser alteradas.

Uma paciente que passou da análise presencial para a análise remota, desde o início da pandemia, fala-me de situações em que a mãe esteve entre a vida e a morte, por doença oncológica e mais tarde por diversas tentativas de suicídio, quando ela ainda era criança. Fala-me destes eventos traumáticos com um detalhe que nunca antes me tinha falado. Na minha escuta, o que eu ouço é: fique com isto dentro de si, tome conta de e resolva. Como se quisesse certificar-se de que eu ouço o trauma, mas, mais do que isso, de que eu fico com ela na minha mente, com o seu sofrimento dentro de mim, mais do que o poder partilhar na sessão comigo. Há um ato de confiança, confia-me estas suas partes, mas também de persuasão, em que há um desejo de que eu fique com isso, como se me dissesse: é seu. Diznos Julie Kristeva, em Webinar (Kristeva \& Scarfone, 2020), que há uma ambiguidade na relação analítica que num setting virtual se torna mais aguda, e essa ambiguidade, além de exigir uma escuta mais atenta, dificulta a interpretação na transferência. Julie Kristeva no mesmo Webinar diz-nos que o analista analisa de uma forma visceral, e que se não ouvirmos o que o paciente nos diz, tudo o que se pode fazer é diplomacia, ou humanitarismo auxiliar, ou farmacologia, mas a vocação analítica é essa convivência com o trauma e sem isso não sobreviveremos ao fenómeno. A situação atual de pandemia e o setting da análise remota expõem-nos mais ao risco de, como anteriormente falamos, ficarmos na sombra desta realidade externa e coletiva, e, por isso, negligenciar a escuta e/ou a interpretação daquilo que o paciente nos traz.

Recebo uma paciente presencialmente no consultório, com os constrangimentos inerentes à pandemia, ainda não lhe conheço o rosto e ela não conhece o meu, falamos por detrás das máscaras. A paciente fala-me do seu medo do vírus, não de ficar doente, mas do medo de transmitir o vírus aos familiares que ama (e que se constituem como grupo de risco pela idade: pais e avós), e diz: «não aguentaria com essa culpa, por isso não me aproximo deles, eu sei que é um medo irracional». Há uma tentação de ignorar estes movimentos, dado o contexto atual e a realidade externa em que assentam, e de não interpretar aquilo que está presente na minha mente (a agressividade da paciente), deixando de lado o inconsciente da paciente e aliando-me a esta aparência de empatia e preocupação da paciente, que também lá está, mas não é só. «A ambiguidade deve ser ouvida e quando o aceitamos, não estamos nem em contenção nem em negação», diz Julie Kristeva (Kristeva \& Scarfone, 2020, p.).

Interrogamo-nos acerca da nossa escuta e das defesas e resistências que estão a ser criadas neste novo setting que reinventamos com o paciente. Quanto mais tempo ficaremos neste setting reinventado, não sabemos. O nosso setting analítico é aquele que vivemos nas nossas análises antes da pandemia planetária, e talvez seja exatamente esse que nos permite agora criar o novo e pensar com esta vitalidade psíquica na nossa mortalidade. Há um apelo à vitalidade do analista, à sua capacidade de se identificar com o trauma e de passar por ele: «a luta da espécie humana é uma luta pela vida», disse Freud em «O mal-estar na civilização» (1930), citado por Julie Kristeva (Kristeva \& Scarfone, 2020, p.).

Dominique Scarfone (Kristeva \& Scarfone, 2020) diz-nos que esta nova visão de corporalidade põe em jogo todas as dimensões sensoriais da experiência analítica e que, em alguns momentos, nos confronta com a presença do corpo como portador do risco dessa presença. Há um aspeto contra fóbico nas relações à distância, uma vez que há menos perigo de passar para o ato corporal, e, portanto, há um tipo de evitamento do perigo que deve estar constantemente presente para que algo do drama psicanalítico tome forma e realmente assuma dimensões fortes o suficiente para não apenas nos preocupar, como sobretudo nos encorajar a ver o quanto estamos comprometidos na relação transferencial. Dominique Scarfone afirma que é certo que a «descorporização» que a análise remota traz é um problema real. O corpo não pode ser reduzido à linguagem verbal e a análise remota comporta o risco de nos fixarmos na linguagem e deixar passar tudo o 
resto que está a acontecer ali, esquecendo a importância da presença não linguística, que pode ser muito sedutora e também muito perturbadora deste corpo que não pode ser completamente traduzido em linguagem.

«No aqui e agora, em que não há outras soluções, devemos aceitar este setting, mas desde que esteja interiorizado nas nossas mentes que o analista faz do contacto presencial com os seus pacientes e que esse é o nosso setting, a nossa estrutura. Analiso com todos os meus sentidos, ouvir é o sentido mais abstrato, mais intelectual, a voz é muito corporal, mas não é suficiente. A posição corporal, os gestos que acompanham as palavras, o cheiro do gabinete e a sensação que contém a desintegração, que é um elemento contra fóbico, que não só contém, mas que empurra a fobia para uma nova encarnação. Portanto, para uma transformação, para uma interpretação através do corpo do outro. O significante passa pelo corpo do outro. Não demonizemos a análise remota, mas vamos aceitá-la como último recurso» (Kristeva \& Scarfone, 2020, p.).

\section{DISCUSSÃO}

Se é verdade que a alteração da psicanálise tradicional para um setting remoto, quando a presença física não é possível, tem sido implementada e discutida desde há vários anos, o contexto pandémico veio introduzir variáveis que exigem outro olhar sobre essa mesma mudança.

Efetivamente, nesta situação, a distância física entre analista e analisando deixa de ser uma escolha (como acontece quando o paciente vai viver para longe e opta por manter o seguimento a distância no lugar de mudar de terapeuta) para se tornar numa imposição externa de uma realidade simultaneamente comum e alheia a ambos. A escolha, neste caso, será continuar ou interromper o tratamento em curso.

Além disso, quando paciente e analista concordam em continuar o trabalho terapêutico numa modalidade virtual, será interessante pensar em quem escolheu esse novo setting (telefone, vídeo, etc.) e se a tomada de decisão reflete aspe- tos da dinâmica transferencial do par analítico. Terá sido uma escolha consensual dos dois? Ou será que o paciente se sentiu submetido à vontade do analista? Ou vice-versa? O analista, por sua vez, deverá optar por um setting em que se sinta mais confortável, ou ter em conta a necessidade/vontade expressa do paciente? Existem formatos mais adequados a determinados tipos de pacientes e problemáticas? Poderemos dizer que os pacientes com uma maior fragilidade dos objetos internos beneficiam mais de um setting remoto com presença de imagem (videoconferência)?

A reflexão destes quatro analistas mostra como a resposta a estas questões não é consensual. Se, por um lado, é partilhada a experiência de que os pacientes com problemáticas de separação e abandono viveram com maior angústia a perda da presença corporal do analista, nem sempre essa questão é compensada com a imagem no ecrã. De facto, no setting remoto há uma perda da presença do analista em dimensões muito profundas e viscerais, impossíveis de substituir com uma imagem virtual - o corpo do analista, a sua respiração, a sua voz e o espaço do consultório são elementos essenciais que suportam os movimentos regressivos dos pacientes. Uma paciente com fortes angústias de separação dizia, já deitada no divã, como tivera saudades das paredes do consultório, que lhe davam um sentimento de limites protetores impossíveis de igualar virtualmente. Mas esta paciente prefere uma análise remota sem imagem, pelo telefone, no qual a simples presença da voz da analista e dos aspetos contentores que ela transporta oferece uma proximidade e intimidade maiores do que a imagem virtual. Para outros pacientes, a experiência a distância é vivida como muito perturbadora, e o setting remoto torna-se numa forma de manter o vínculo, mas suspendendo um trabalho mais profundo e interpretativo.

Ou talvez a resposta a esta questão esteja fundamentalmente relacionada com o par analítico, e aquilo que a ambos deixa mais confortável. Em todo o caso, cabe-nos a nós moldarmo-nos ao paciente, mantendo sempre intacta a nossa identidade como analistas, assim como a mãe se adapta 
ao bebé, mantendo intacta a sua identidade e o seu papel.

Masalém da necessidade deumsettinganalítico remoto, o contexto pandémico, pelas suas características associadas à imposição de uma nova realidade súbita, brutal e universal, ligada a uma ameaça de morte, trouxe para o campo analítico uma série de fantasmas psíquicos: a angústia de morte e de ruína, a vivência claustrofóbica ou de evitamento fóbico com o confinamento obrigatório, as angústias de separação com o distanciamento social (no setting e fora dele), os fantasmas paranoides com o clima de perigo e incerteza, o estranho. A experiência partilhada destes quatro analistas revela como este acordar de fantasmas se pode tornar numa oportunidade para trabalhar questões que permaneciam mais ou menos «adormecidas» ou «pré-conscientes», tornando-se assim num impulsionador de evolução psíquica. Se é verdade que a pandemia constituiu a intrusão de uma realidade externa e factual no contexto analítico, também sabemos que o trabalho em psicanálise não se limita a um processo laboratorial de exploração da realidade interna e do inconsciente, mas que atua no espaço entre a realidade externa e interna - à semelhança de um teste projetivo, onde é a imagem desencadeada a partir de uma realidade percetiva que nos dá acesso ao mundo interno -, no espaço potencial entre duas mentes (analista e analisando) e dois espaços (o espaço da realidade factual e da realidade psíquica). E, nesse sentido, a realidade pandémica foi esse novo real, que criou um novo espaço potencial, possibilitando novos materiais a ser trabalhados.

Por outro lado, se é verdade que a pandemia nos mergulhou a todos numa realidade hiperconcreta - que nos inundou em números, estatísticas e medidas sanitárias, deixando pouco espaço ao sonho, ao simbólico, à criatividade -, o contexto analítico, enquanto espaço de escuta de fantasmas e criação de palavras, pode tornar-se, mesmo sem a presença do corpo, justamente num antídoto contra essa concretude, e um impulso criativo e transformador.

Finalmente, a pandemia enquanto situação de crise revelou-se também, em muitas situa- ções, um impulso para a autonomia e maturidade: alguns pacientes tiveram de se separar e proteger os pais mais vulneráveis à doença, e olhar para um analista menos idealizado, mais humano, também vulnerável ao real, promovendo aqui a «preocupação com o objeto» (Winnicott, 1983) e o luto do analista enquanto objeto ideal/omnipotente.

Que consequências terá a pandemia Covid-19 para o Futuro da Psicanálise? Da mesma forma que podemos imaginar que o recurso ao teletrabalho e à tele-escola irá introduzir mudanças de comportamento que irão perdurar para lá do tempo pandémico, que no futuro existirão mais empresas virtuais, mais pessoas a trabalhar em casa e mais ensino à distância, podemos imaginar repercussões no setting psicanalítico? Terá o setting remoto «convencido» os analistas mais resistentes ao tratamento a distância? Passará ele a ser utilizado também por razões de «comodismo», como, por exemplo, um paciente que vai subitamente de férias e que no lugar de interromper as sessões, continuando a pagá-las, opta por as fazer a distância a partir de qualquer lugar do mundo? Que capacidade terá isto na capacidade de escolha e de renúncia? E de compromisso? E de separação?

É inquestionável que esta nova realidade que nos deixou sem alternativas revelou a importância da Psicanálise de se adaptar ao real e se reinventar. Sendo indiscutível que a relação intersubjetiva «virtual»é mais pobre, em qualquer relação intersubjetiva, fora de um contexto terapêutico, onde o corpo fornece mensagens infraverbais e inconscientes que constituem uma fonte rica de informação, no caso da Psicanálise, somam-se outros elementos do seu setting - a proximidade corporal, o cheiro, a respiração, os silêncios, o espaço contentor, a assimetria das cadeiras -, que tendem mais facilmente a evocar os fantasmas ligados à sexualidade infantil, tornando possível uma contratransferência mais marcada, mais primária, ferramentas essenciais no trabalho analítico. Mas esta crise veio confirmar que é possível trabalhar a distância, não só como forma de dar continuidade ao processo de tratamento, como também utilizando o material terapêutico que 
essa alteração de setting suscita, como é o caso das questões ligadas à separação, assim esteja o analista a fazer uso da sua função analítica de escuta daquilo que surge.

Além disso, a ausência física (temporária) do analista poderá talvez tornar-se numa outra via para o trabalho do negativo (Green, 1982, 1993, apud Garcia \& Penna, 2010):

«O trabalho do negativo que pode apresentar-se de diferentes formas, entre dois extremos que, grosso modo, podemos considerar como bem-sucedido, quando possibilita o surgimento de uma ausência que é presença em potencial, ou malsucedido, quando resulta num excesso mortífero, por ausência ou por presença. Assim, o trabalho do negativo pode assumir feições patológicas ou estruturantes, caso em que a descontinuidade que provoca redunda na construção dos limites psíquicos saudáveis. As ruturas têm uma função psíquica estruturante pela criação de um vazio, de um espaço no psiquismo no qual os limites intrapsíquicos, as representações, o pensamento e as relações de objeto podem adquirir forma.» (p. 5)

Finalmente, da mesma forma que o confinamento pandémico criou uma confusão de espaços - misturam-se o espaço-família, espaço-trabalho, espaço-escola - , o setting «a partir de casa» não criará também essa confusão, retirando o espaço (real e simbólico) do consultório para onde o paciente tem de ir e regressar e o tempo (real e simbólico) nessa mesma deslocação? Um espaço-tempo também de elaboração psíquica? Que consequências analíticas terá este espaço-tempo «enlatado» no meio de outras atividades (laborais, domésticas, familiares) para ambos, paciente e analista?

Estas são questões à espera de continuarem a ser pensadas. Esse é, talvez, o único setting que não podemos alterar - a capacidade de manter sempre, e para lá do espaço físico, a atitude analítica, a escuta do inconsciente e dos movimentos transfero-contratransferenciais. Podemos alterar o cenário, mas é crucial manter o mesmo olhar-escuta sobre a «dramaturgia» que ali surge.

\section{BIBLIOGRAFIA}

Abraham, N. \& Torok, M. (1995). A casca e o núcleo. Escuta. (Obra original publicada em 1972.)

Aryan, A. (2013). Setting and transference-countertransference reconsidered on beginning teleanalysis. In J. S. Scharff (Ed.), Psychoanalysis online, mental health, teletherapy and training. Karnac Books.

Bion, W. R. (1970). Attention and interpretation. Karnac Books.

Cabré, L. M. (2020a). Webminar «Procesamiento de la situación traumática y el aislamiento social», International Psychoanalytical Association, 3 de abril.

Cabré, L. M. (2020b). El desafio del coronavírus y su manejo clínico. In M. J. Gonçalves; C. Farate; D. Kraunt; L. M. Cabré \& R. A. Oliveira, Ética e Psicanálise à Distância. Revista Portuguesa de Psicanálise, 40(2), 77-81.

Cintra, E. M. (2013). André Green e o trabalho do negativo. Revista Percurso, 49/50, Ano XXV, junho: http://revistapercurso.uol.com.br/index.php?apg=artigo_view\&ida=1010\&ori=edicao\&id_edicao $=49$

Dias, C. A. (2004). Costurando as linhas da psicopatologia borderland (estados limite). Climepsi Editores.

Diena, S. (2020). Entrevista IPA Off the Couch, Ep. 41, 25 de março: http://ipaoffthecouch. org/2020/03/24/episode-41-report-from-milan-with-simonetta-diena-md/

Ehrlich, L. (2019). Teleanalysis: Slippery slope or rich opportunity? Journal of the American Pyschoanalytic Association, 67: 249-279.

Fairbairn, R. (2000) Estudos Psicanaliticos da personalidade. Veja.

Ferenczi, S. (2011). A elasticidade da técnica psicanalítica. In Obras Completas: Psicanálise IV. Martins Fontes. (Trabalho original publicado em 1928.)

Ferro, A. (2009). Mind Works. Technique and Creativity in Psychoanalysis. General Editor.

Franco, S. (2003). Psicopatologia e o viver criativo. Revista Latinoamericana Psicopatologia Fundamental, VI(2), 36-50.

Garcia, C; Penna, C (2010). O Trabalho do Neg- 
ativo e a Transmissão Psíquica. Arquivos Brasileiros de Psicologia, 62(3): http://pepsic. bvsalud.org/scielo.php?script=sci_arttext\&pid=S1809-52672010000300009

Gutiérrez, L. (2017). Silicon in 'pure gold'? Theoretical contributions and observations on teleanalysis by videoconference. International Journal of Psychoanalysis, 98,1097-1120.

Hardt, J. (2019). Does Psychoanalysis go online without Body?. EPF Publication "Body", 73: $83-88$.

Hárs, G.P. (2015) O conceito de paixão no Diário Clínico de Ferenczi. Tempo Psicanalítico, vol. 47.1, 9-21.

Khan, M (1963). The concept of cumulative trauma. Psychoanaytical Study of the Child, 18, 286-306.

Kristeva, J. \& Scarfone, D. (2020). La situation virale et ses resonances psychanalytiques. International Psychoanalytical Association Webinar.

Kogan, I (2020). Entrevista IPA Off the Couch, Ep. 67, 27 de setembro: http://ipaoffthecouch. org/2020/09/27/episode-67-creativity-inthe-analyst-and-analysand-in-times-ofcovid-with-ilany-kogan/

Komarova, L. (2020). Entrevista IPA Off the Couch, Ep. 57, 28 de junho: http://ipaoffthecouch. org/2020/06/28/episode-57-a-report-from-moscow-and-the-role-of-denial-with-lola-komarova-ph-d/

Lemma, A. (2014). The body of the analyst and the analytic setting: Reflections on the embodied setting and the symbiotic transference. International Journal of Psychoanalysis, $95,225-244$.

Lemma, A. (2015). Psychoanalysis in the time of technoculture: Some reflections on the fate of the body in virtual space. The International Journal of Psychoanalysis, 96, 569-582.

Marta, R. (2011). A Linguagem do Silencio: transformando analista e paciente. Revista Portuguesa de Psicanálise, 30(2),

Marta, R. (2016). Relações reais e/ou virtuais? A psicanálise remota. Revista Portuguesa de Psicanálise, 37(2),

Marta, R. (2019). O analista tem corpo? Transformações do corpo em análise. Revista Portuguesa de Psicanálise, 40 (1), 42-51.

Marta, R. (2020). O Real, o Tempo e o Espaço em Tempos de Corona. A Peste - Blogue da Sociedade Portuguesa de Psicanálise. Maio.

Matos, A. C. (2014). Depressão. Climepsi Editores. Miguez, T. (2021). Desafios à Psicanálise e à sua Criatividade. A Peste - Blogue da Sociedade Portuguesa de Psicanálise. Março.

Miller, J. A. (2004). Uma fantasia. Opção Lacaniana. Eolia, 42(3,) 7-18.

Miller, P. (2019). Working Through the Body Ego in the Analytic Process. EPF Publication "Body", 73, 134-141.

Nacht, S. (1964). Silence as an integrative factor. The International Journal of Psychoanalysis, 45(2/5), 299-303.

Ogden, T. H. (1985). On potential space. International Journal of Psychoanalysis, 66(2), 129141.

Ogden, T. H. (2010). Esta Arte da Psicanálise. Artmed Editora.

Samuel, Y. (2020). Entrevista IPA Off the Couch, Ep .41, 26 de abril: http://ipaoffthecouch. org/2020/04/26/episode-49-a-report-from-tel-aviv-with-yael-samuel-phd/

Scarfone, D. (2015). The time before us. (The Unpast in W. S. Merwin, W. Benjamin and V. Woolf.). Psychoanalytical Dialogues, 26(5), 513-520.

Scharff, J. (2012). Clinical issues in analyses over the telephone and the internet. International Journal of Psychoanalysis, 93, 81-95.

Winnicott, D. (1967). O brincar e a realidade. Imago.

Winnicott, D. W. (1983). O desenvolvimento da capacidade de se preocupar. In D. W. Winnicott, O ambiente e os processos de maturação: estudos sobre a teoria do desenvolvimento emocional (pp. 70-78). Artes Médicas. (Obra original publicado em 1963.) 


\title{
The Clinical Practice in Quarentine (A Four Hands Play): First Step of Psy- choanalysis in Pandemic Times
}

\begin{abstract}
With the emergence of the pandemic, in the beginning of 2020, the physical proximity between analyst and analysand became not only prohibited, but dangerous .... Suddenly, analysts were forced to close the office doors, and if some suspended the work with patients, most started work remotely teleanalysis (by phone or internet - Skype, Zoom, WhatsApp, etc.).

Four analysts reflect on their experience in adjusting the setting in times of a pandemic: the specificity of the pandemic situation in relation to other situations in which the external reality requires the use of the remote setting; the different way in which the pandemic and the necessary alteration of the setting were experienced by different patients, and by different analysts, showing how psychoanalysis works with the analytical field and how each dyad, in the transference-countertransference relationship, makes what happens there unique.

From this multiple experience of four analysts "playing" together their unique experience, just as musicians can play together a single sonata, each with its different melody, it was possible to raise a series of questions at the end.
\end{abstract}

